\title{
The establishment of rainfall thresholds for debris slide in Taiwan - with the combination of multivariate analysis and the I-R index
}

\author{
Lun-Wei Wei ${ }^{\text {i) }}$, Hsi-Hung Lin ${ }^{\text {ii) }}$ and Chung-Chi Chi ${ }^{\text {iii) }}$
}

i) Associate Researcher, Disaster Prevention Technology Research Center, Sinotech Engineering Consultants, INC., No. 280, Xinhu $2^{\text {nd }}$ Rd., Neihu Dist., Taipei City 11494, Taiwan.

ii) Associate Technical Specialist, Central Geological Survey, Ministry of Economic Affairs, No. 2, Ln. 109, Huaxin St., Zhonghe Dist., New Taipei City 23568, Taiwan.

iii) Section Chief, Central Geological Survey, Ministry of Economic Affairs, No. 2, Ln. 109, Huaxin St., Zhonghe Dist., New Taipei City 23568, Taiwan.

\begin{abstract}
Catastrophic landslides and debris slides triggered by intense typhoons such as Typhoon Morakot (2009) occurred more frequently in the recent years, and caused many casualties and economic loss in Taiwan. For the purpose of reducing the damage resulted from geological hazards, this study collects landslide inventories which contain the information of occurrence time, location, magnitude, rainfall intensity, accumulated rainfall and tries to establish the rainfall threshold for debris slide. This study adopts the concept of risk matrix, combining the magnitude (landslide ratio of slope units) and the possibility of occurrence (historical disaster records) to set up the warning thresholds. Critical rainfall thresholds are build up according to the $\mathrm{R}_{24}$ (24 hours accumulated rainfall, as long-term rainfall) and $\mathrm{I}_{3}$ (3 hourly mean rainfall intensity, as short-term rainfall) of historical disasters. Validation with recent typhoon event shows the threshold can forecast the landslides in 2 9 hours in advance which may be enough for the evacuation. An early-warning system is also built and the results can be applied to regional land-use planning and disaster prevention.
\end{abstract}

Keywords: landslide warning, debris slide, landslide susceptibility, rainfall threshold

\section{INTRODUCTION}

Debris slide is the slide of weathered materials on the slope which can be considered as shallow landslide. The rainfall thresholds for the debris slide had been well discussed and concluded in the past (Hungr et al., 2001; Guzzetti et al., 2007). These thresholds can mainly classified into 5 categories including intensity-duration (Brunetti et al., 2010; Zhou et al., 2014), accumulated rainfall-duration (Martelloni, 2011; Vessia et al., 2014), accumulated rainfall (Corominas and Moya, 1999; Bell and Maud, 2000), intensity-accumulated rainfall (Hong et al., 2005) and accumulated rainfall-accumulated rainfall (Osanai et al., 2010; Turkington et al., 2014).

However, the rainfall thresholds may overestimate or underestimate if the magnitude of landslide didn't taking into consideration. Thus, the aim of this study is trying to combine the magnitude of landslide and the method of evaluating rainfall thresholds as well as the concept of risk matrix to establish the rainfall thresholds for slope unit in Taiwan. This work also explores the relationship between the landslide and rainfall characteristics and finds that 3 hours mean rainfall intensity and 24 hours accumulated rainfall are the most dominant parameter, thus, the $\mathrm{I}_{3}-\mathrm{R}_{24}$ threshold are established and validated for the purpose of further applications. Finally, with the connection of real-time rainfall data (QPESUMS, Quantitative Precipitation Estimation and Segregation Using Multiple Sensor), a landslide evaluation system is also established for the purpose of early warning.

\section{STUDY AREA}

Taiwan is located at the western Pacific Ocean, the convergent plate boundary zone of Philippine Sea plate and Eurasian plate. There are hundreds of faults and folds in the 36,000 $\mathrm{km}^{2}$ area because of the tectonic activity. Typhoons and monsoons bring lots of rainfall which is estimated $2,500 \mathrm{~mm}$, even more than 3,000 $\mathrm{mm}$ in mountainous areas every year (Hsu, 2013). As a result, the exhumation rate in Taiwan is about 3 to 6 $\mathrm{mm}$ /year (Dadson et al., 2003), mainly are caused from the landslide process. On the other hand, the population in Taiwan is about 2.3 millions, high population density 
and the frequent nature disasters make Taiwan one of the countries that most exposed to multiple hazards (Dilley et al., 2005).

This study divided Taiwan into 4 main regions including the northern, the central, the southern and the eastern Taiwan (Fig.1). These areas are the most populated as well as facing the threat of landslide.

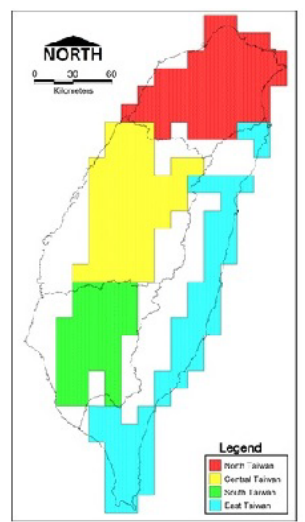

Fig. 1. Regions of study area.

\section{METHOD}

The aim of this study is trying to establish the rainfall thresholds for the debris slide, thus, the landslide must be interpreted firstly to build up the landslide inventory. After that, field investigation is needed to check the results of interpretation, the mechanism and the geological condition of each landslide. The occurrence time of landslides is crucial information when establishing the rainfall thresholds, therefore, this research also visit the village chief and the resident around the landslide to record the data demanded. With occurrence time, accumulated rainfall and the rainfall intensity can be calculated. Combining the results of landslide susceptibility and the historical landslide cases, the rainfall thresholds hereby can be established and an early-warning system can also build for the sake of reducing the loss of life and wealth.

\subsection{Landslide inventory and field investigation}

Landslides can be interpreted through the usage of remote sensing images such as aerial photos or satellite images according to the texture, shape and topographical characteristics of landslide (Asselenand and Seijmonsbergen, 2006; Moine et al., 2009; Mondini et al., 2011; Stumpf and Kerle, 2011; Martha et al., 2012; Razak et al., 2013). This study follows the rules proposed by Soeters and Van Westen (1996) and uses SPOT image (resolution: $2.5 \mathrm{~m} \times 2.5 \mathrm{~m}$ ) before and after 16 typhoon events for the interpretation of landslides induced by heavy rainfall. Field investigation is needed for the validation of interpretation (Fig. 2). The detailed information such as mechanism, lithology, geological structure, joint, strength of rocks, depth of landslide should also record for further analysis.
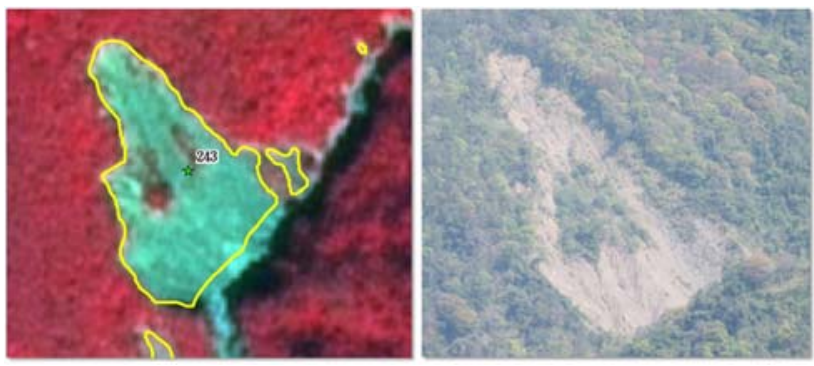

Fig. 2. Landslide interpretation and the picture took during the field investigation.

\subsection{Records of occurrence time of landslide and the Landslide Disasters Database (LDD)}

Rainfall conditions that induced landslides are key data while applying the empirical method to establish the rainfall thresholds for debris slide (Guzzetti et al., 2007, 2008; Brunetti et al., 2010). A total 949 cases which contain the information of occurrence time of landslide are collected during the field investigation (Fig. 3). Besides, for the purpose of conserving these valuable records and providing for further analysis, a Landslide Disasters Database was built (Fig. 4). This database consists of 4 parts: (1) basic data, such as location, occurrence time, typhoon event, area, geological condition, geomorphological condition; (2) map, which shows the location of landslide; (3) pictures of the investigation, highlighting important features; (4) attached files of reports on the landslide. The database benefits government collecting landslide cases systematically.

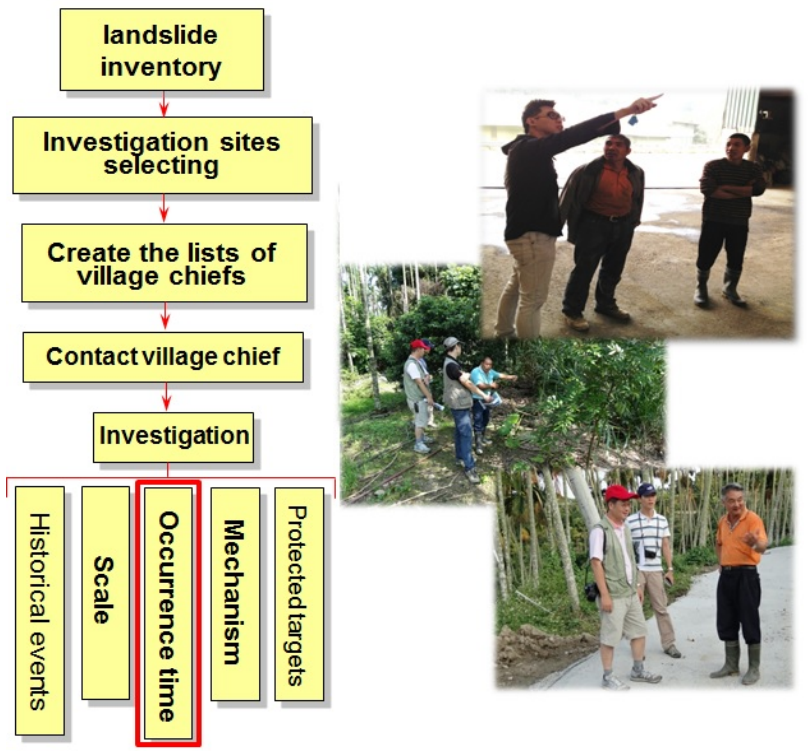

Fig. 3. Flowchart of recording the occurrence time of landslide during field investigation. 

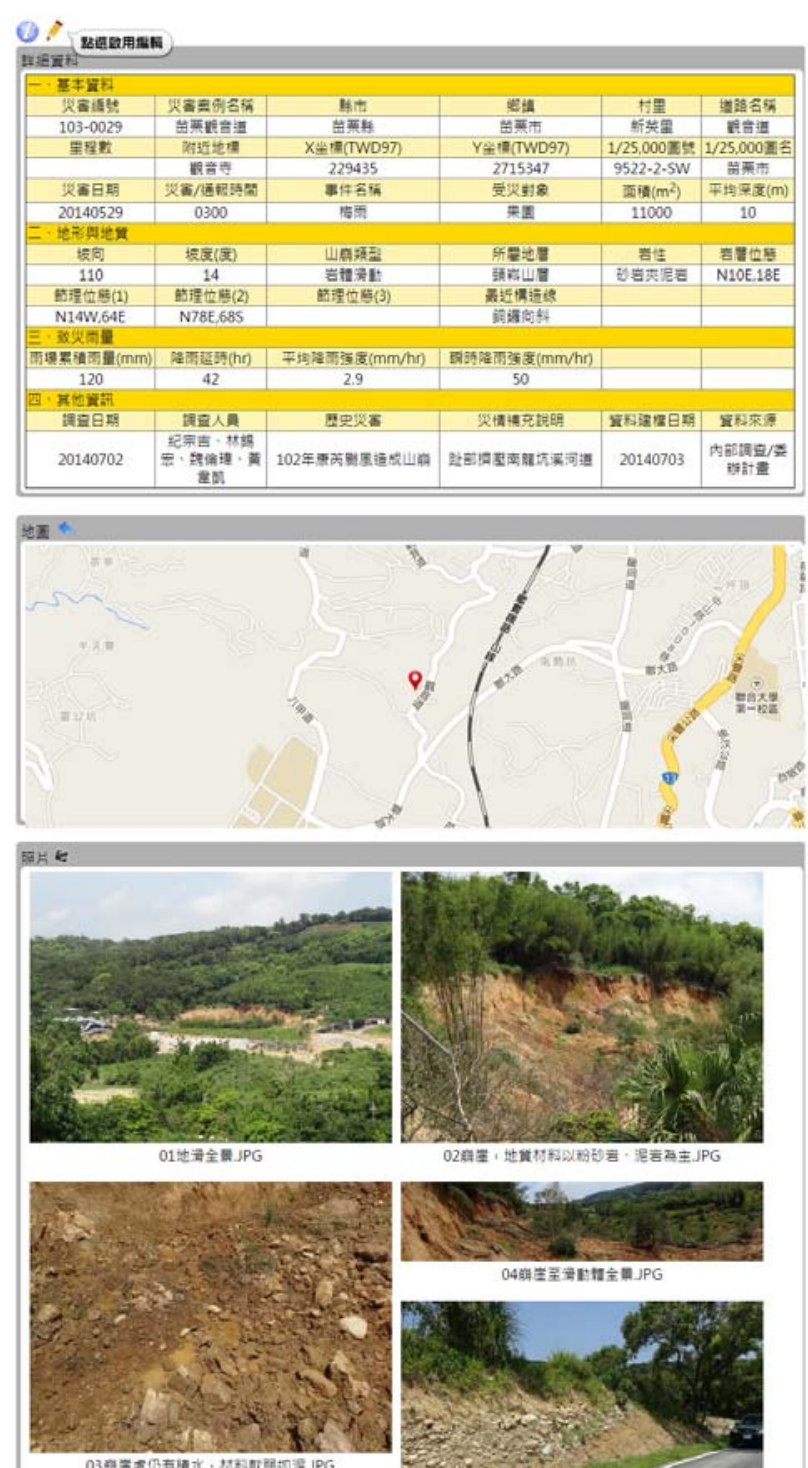

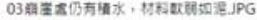
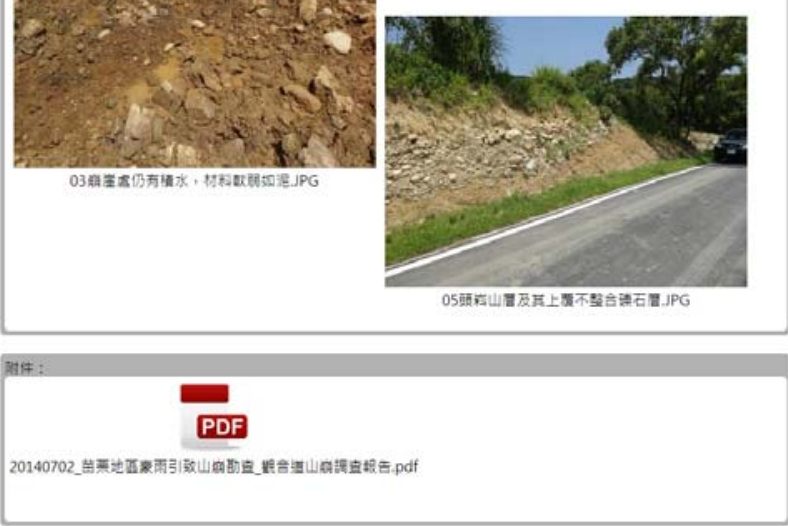

Fig. 4. Landslide Disasters Database (LDD) which helps collecting landslide cases systematically.

\subsection{Analysis of rainfall data}

Based on the occurrence time of each landslide, rainfall data was collected and analyzed to understand the rainfall condition. In Taiwan, both high intensity and long duration rainfall events can cause severe disasters (Chen et al., 2006; Wu et al., 2011; Wei et al., 2014; Lee et al., 2015), thus, this study uses 3-hours mean rainfall intensity $\left(\mathrm{I}_{3}\right)$ as short-term rainfall index and 24-hours accumulated rainfall $\left(\mathrm{R}_{24}\right)$ as long-term index (Liao et al., 2010). The definition of a rainfall event is as followed: A rainfall event is started when the hourly rainfall is greater than $4 \mathrm{~mm}$ and comes to the end when the rainfall is continuously lower than 4 $\mathrm{mm}$ for 6 hours. Fig. 5 shows the method for calculating the rainfall indexes. If the landslide is occurred at $i$ hour, $\mathrm{I}_{3}$ is the mean value of the rainfall within $i, i-1, i-2$ hours and $\mathrm{R}_{24}$ is the summation of the rainfall within $i$ to $i-23$ hours.

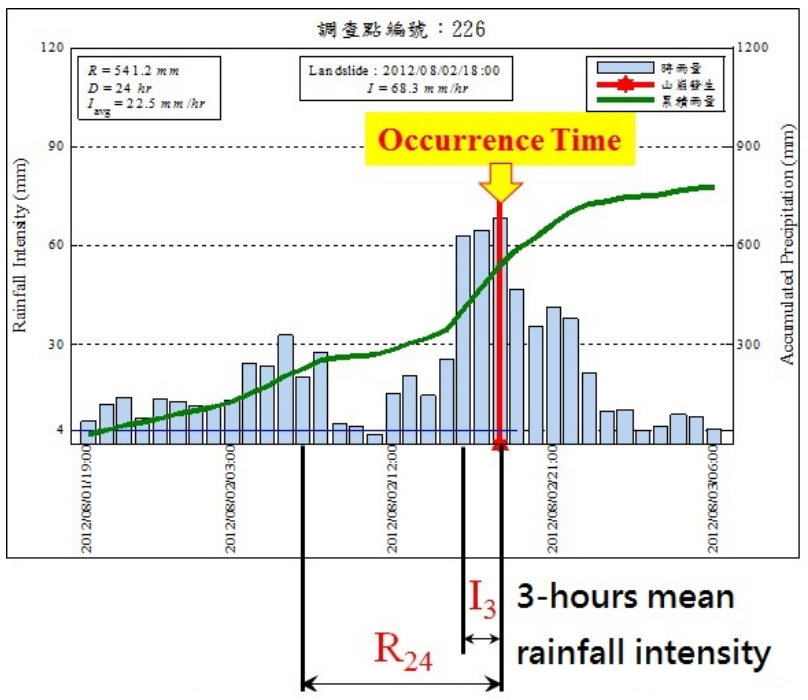

\section{4-hours accumulated rainfall}

Fig. 5. Rainfall indexes used in the study.

\subsection{Slope unit}

For the purpose of the application in disaster prevention, this study uses slope unit as mapping unit (Guzzetti et al., 1999; Xie et al., 2004; Fig. 6). Slope unit is a kind of mapping unit that based on the features of geomorphology such as ridges and river valleys. Each slope unit can be given a unique number and the government can issued a warning toward a specific slope during the rainfall event. This will also lift the efficiency of evacuation.

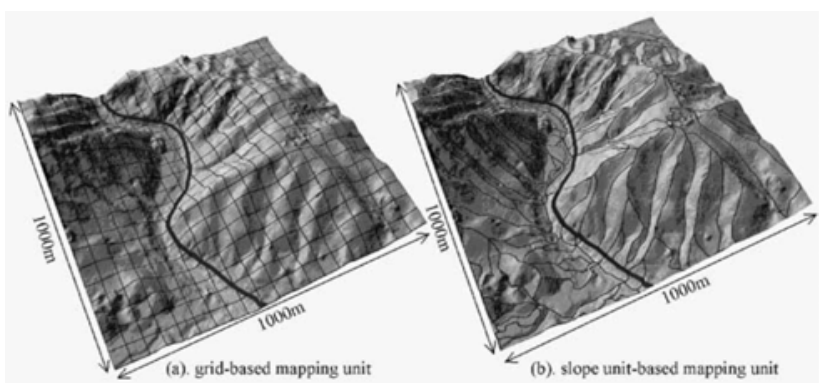

Fig. 6. (a) Grid-based mapping unit and (b) slope unit-based mapping unit (Xie et al., 2004). Slope unit can lift the efficiency of disaster mitigation during rainfall events.

\subsection{Landslide susceptibility analysis}

Logistic regression method is applied in this study to evaluate the susceptibility of each slope units 
(Guzzetti et al., 1999; Ayalew and Yamagishi, 2005, Cheng et al., 2013). Geological, topographical and triggering factors such as lithology, strength of rock, gradient, height of slope, rainfall intensity and accumulated rainfall are considered to develop landslide susceptibility model (Fig. 7). Validation is also performed with landslide inventory to verify the model.

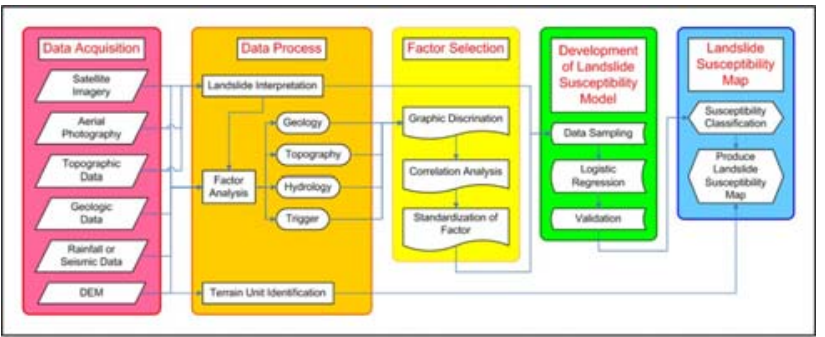

Fig. 7. The flowchart of developing landslide susceptibility model.

\subsection{Rainfall threshold for debris slide}

Logistic regression method is applied in this study to calculate the susceptibility of each slope units. It is found that when the susceptibility of the slope unit is higher, the landslide ratio of the slope unit (landslide area within a slope unit divided by the area of slope unit) is also greater. According to this phenomenon, slope units are categorized into Type I (high susceptibility and landslide ratio of slope unit is greater than 0.2), Type II (moderate susceptibility and landslide ratio is between 0.1 to 0.2 ), Type III (low susceptibility and landslide ratio is lower than 0.1 ), and the rainfall thresholds for each type are setup separately.

After analyzing more than 900 cases, 3 hours mean rainfall intensity and 24 hours accumulated rainfall are chosen as the index for establishing rainfall thresholds for debris slide (Wei et al., 2015). Historical records of landslides are plotted in the diagram (Fig. 8.), and the ellipse is used to determine the envelope of historical cases according to the distribution of data. The parameter $\mathrm{a}$ and $\mathrm{b}$ of ellipse are set according to the slope of regression line by applying least square method. The thresholds are determined according to the percentage of historical cases that included by the envelope, i.e. the $90 \%$ threshold includes $90 \%$ of the historical cases. It means that if the rainfall condition exceeds this threshold, the probability of occurring landslides is extremely high.

This study also takes the magnitude of landslide into consideration and gives the warning signal with the concept of hazard matrix (Fig. 9.). The magnitude of landslide is classified into 3 categories according to the landslide ratio of slope units mentioned in the first paragraph in this section. If the landslide magnitude (the landslide ratio of the slope unit) is giant and the probability of occurrence is high, it is assigned as red signal which means high danger; on the other hand, if the magnitude (the landslide ratio of the slope unit) is small and the probability is low, it is assigned as green signal which means general condition.

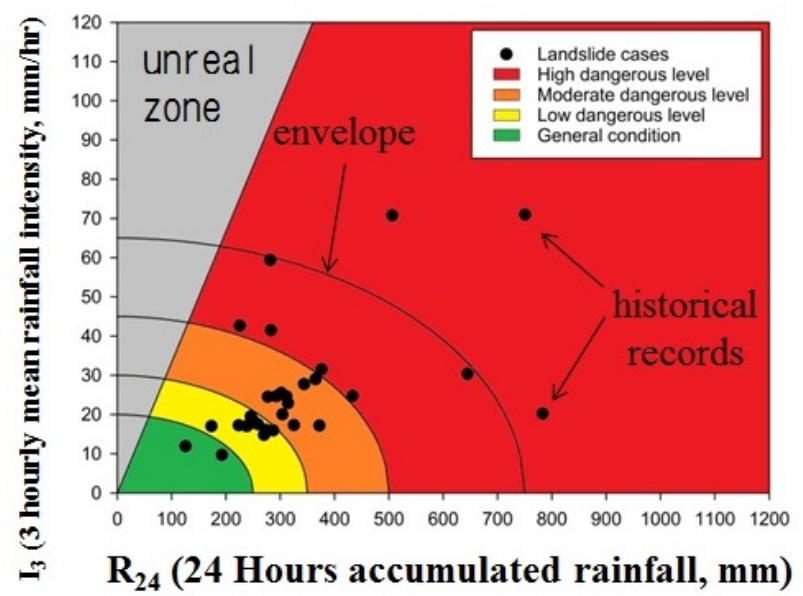

Fig. 8. Establishing rainfall thresholds by adopting $\mathrm{I}_{3}$ and $\mathrm{R}_{24}$ as index to evaluate the probability of occurring landslides under different rainfall conditions.

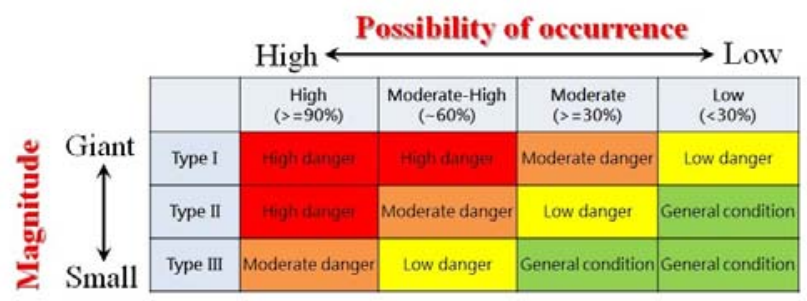

Fig. 9. Setting of warning signals combining the magnitude, the possibility of occurrence and the concept of risk matrix.

\section{RESULTS AND VALIDATIONS}

\subsection{Results}

Taiwan was divided into 4 main regions (Fig. 1.) and the preliminary rainfall threshold for each magnitude in each region was established (Fig. 10.). These thresholds also reflect the complexity and the difference of geology and climate in each region. For example, the northern Taiwan is mainly consisting of volcanic and metamorphic rocks while the southern Taiwan is mainly sedimentary and metamorphic rocks, but the MAP (mean annual precipitation) is higher in southern Taiwan, thus it shows a slightly higher threshold to induce new landslide in southern Taiwan. 


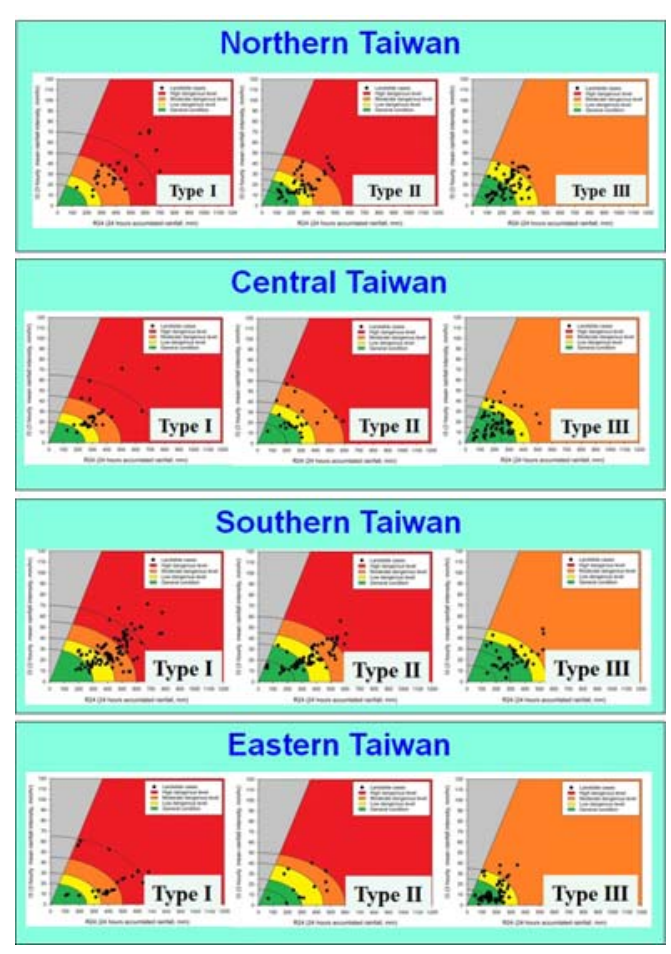

Fig. 10. Preliminary rainfall thresholds in Taiwan. There are 4 main regions and 3 main types of magnitude in each region.

\subsection{Validation}

Validations are performed with landslide cases during the Typhoon Matmo, July, 2014. It is showed that newly occurred landslides can be forecasted 2 to 9 hours in advanced with red or orange signal according to the snake line in the graph (Fig. 11.), providing valuable information for the disaster prevention. It is also find that for the existing landslides, it may re-occur during the yellow signal period. This phenomenon implies that there is a much lower threshold for the pre-existing landslides. Two ways may solve this problem: one is establishing another threshold for the pre-existing landslides and another is lowering the threshold for warning (i.e. announcing warning when the signal turns to yellow). However, more cases for the validation are still needed before taking into practice.

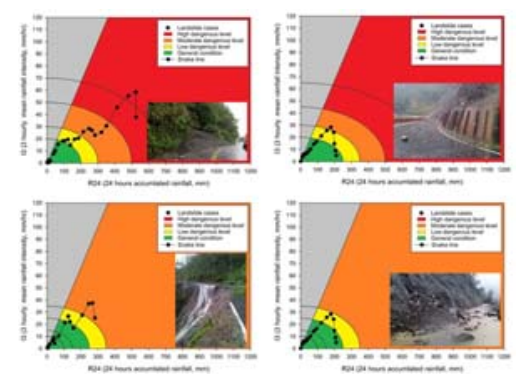

Fig. 11. Validations of the rainfall thresholds show that newly occurred landslides can be forecasted 2 to 9 hours in advanced, providing valuable information for disaster prevention.

\section{RAINFALL-INDUCED LANDSLIDE EARLY WARNING INFORMATION SYSTEM (RILEWIS)}

A real-time warning system is built for the purpose of early warning (Fig. 12.). This system is connected with real-time rainfall data. As the rainfall increases, the system can calculate the snake line immediately (shown as in Fig. 11.) and provide the information of the stability of slopes (Fig. 13.).

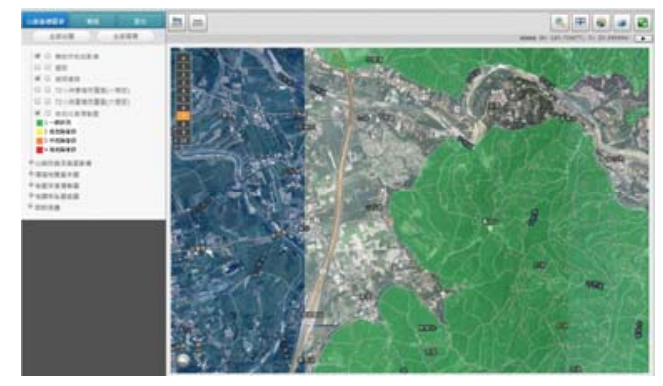

Fig.12. The Rainfall-induced Landslide Early Warning Information System (RiLEWIS) is connected with real-time rainfall data and providing the information of the stability of slopes.

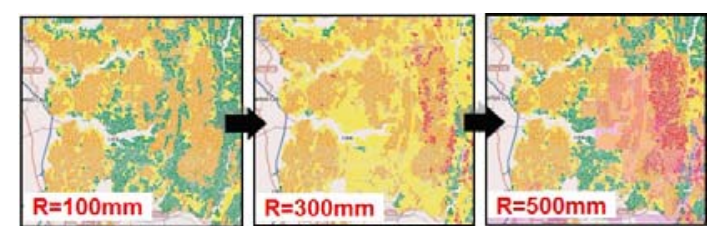

Fig.13. The warning signal of each slope unit is calculated automatically according to the rainfall. As rainfall increases, the signal will turn to orange or red indicating that the possibility of failure is higher.

\section{CONCLUSIONS}

This study classifies landslide magnitude into 3 categories and establishes the rainfall threshold separately. The combination of magnitude, possibility of occurrence and the concept of risk matrix can setup warning signals in a more intuitional way for the decision of evacuation. Preliminary validation shows that the results is acceptable and can be used for further test on landslide forecasting. An early-warning system is also built to connect the real-time rainfall data and calculating the warning levels immediately for the purpose of disaster prevention and may increase the response time for evacuation.

\section{ACKNOWLEDGEMENTS}

The authors would like to thank the Central Geological Survey, Taiwan, for supporting this research financially and providing helpful comments on the research.

\section{REFERENCES}

1) Asselenand, S. V. and Seijmonsbergen A. C. (2006): 
Expert-driven semi-automated geomorphological mapping for a mountainous area using a laser DTM. Geomorphology, 78(3-4), 309-320.

2) Ayalew, L. and Yamagishi, H. (2005): The application of GIS-based logistic regression for landslide susceptibility mapping in the Kakuda-Yahiko Mountains, Central Japan. Geomorphology, 65(1), 15-31.

3) Bell, F. G. and Maud, R. R. (2000): Landslides associated with the colluvial soils overlying the Natal Group in the greater Durban region of Natal, South Africa. Environmental Geology, 39(9), 1029-1038.

4) Brunetti M.T., Peruccacci S., Rossi M., Luciani S., Valigi D. and Guzzetti F. (2010): Rainfall thresholds for the possible occurrence of landslides in Italy, Nat. Hazards Earth Syst. Sci., 10(3), 447-458.

5) Chen, H., Dadson, S. and Chi, Y. G. (2006): Recent rainfall-induced landslides and debris flow in northern Taiwan. Geomorphology, 77(1), 112-125.

6) Cheng, C. T., Huang, C. M., Wei, L. W., Lee, C. F., Lee, C. T. (2013): Landslide Susceptibility Map. ICL Landslide Teaching Tools, ISBN: 978-4-9903382-2-0, 50-55.

7) Corominas, J. and Moya, J. (1999): Reconstructing recent landslide activity in relation to rainfall in the Llobregat River basin, Eastern Pyrences, Spain. Geomorphology, 30, 79-93.

8) Dadson, S. J., Hovius, N., Chen, H., Dade, W. B., Hsieh, M. L., Willett, S. D., Hu, J. C., Horng, M. J., Chen, M. C., Stark, C. P., Lague, D. and Lin, J. C. (2003): Links between erosion, runoff variability and seismicity in the Taiwan orogen. Nature, 426(6967), 648-651.

9) Dilley, M., Chen, R. S., Deichmann, U., Lerner-Lam, A.L. and Arnold, M. (2005): Natural disaster hotspots: a global risk analysis, ISBN 0-8213-5930-4, World Bank Publications.

10) Guzzetti, F., Carrara, A., Cardinali, M. and Reichenbach, P. (1999). Landslide hazard evaluation: a review of current techniques and their application in a multi-scale study, Central Italy. Geomorphology, 31(1), 181-216.

11) Guzzetti, F., Peruccacci, S., Rossi, M. and Stark, C. P. (2007): Rainfall thresholds for the initiation of landslides in central and southern Europe. Meteorology and atmospheric physics, 98(3-4), 239-267.

12) Guzzetti, F., Peruccacci, S., Rossi, M. and Stark, C. P. (2008). The rainfall intensity-duration control of shallow landslides and debris flows: an update. Landslides, 5(1), 3-17.

13) Hong, Y., Hiura, H., Shino, K., Sassa, K., Suemine, A., Fukuoka, H. and Wang, G. (2005): The influence of intense rainfall on the activity of large-scale crystalline schist landslides in Shikoku Island, Japan. Landslides, 2(2), 97-105.

14) Hsu, L. H., Kuo, H. C. and Fovell, R. G. (2013): On the geographic asymmetry of typhoon translation speed across the mountainous island of Taiwan. Journal of the Atmospheric Sciences, 70(4), 1006-1022.

15) Hungr, O., Evans, S.G., Bovis, M.J., Hutchinson, J.N., 2001. A review of the classification of landslides of the flow type. Environmental and Engineering Geoscience 7, 221-238.

16) Lee, C. F., Huang, W. K., Wei, L. W., Tsao, T. C., Chang, Y. L., and Chi, S. Y. (2015). Establishing Landslide Susceptibility Along a Coastal Range Highway in Eastern Taiwan. Engineering Geology for Society and Territory, 2, 1585-1591.

17) Liao, Z., Hong, Y., Wang, J., Fukuoka, H., Sassa, K., Karnawati, D. and Fathani, F. (2010): Prototyping an experimental early warning system for rainfall-induced landslides in Indonesia using satellite remote sensing and geospatial datasets. Landslides, 7(3), 317-324.
18) Martelloni, G., Segoni, S., Fanti, R. and Catani, F. (2011): Rainfall thresholds for the forecasting of landslide occurrence at regional scale. Landslides, 9(4), 485-495.

19) Martha, T. R., Kerle, N., van Westen, C. J., Jetten, V. and Vinod Kumar, K. (2012): Object-oriented analysis of multi-temporal panchromatic images for creation of historical landslide inventories. ISPRS Journal of Photogrammetry and Remote Sensing, 67, 105-119.

20) Moine, M., Puissant, A. and Malet, J. P. (2009): Detection of landslides from aerial and satellite images with a semi-automatic method. Application to the Barcelonnette basin (Alpes-de-Hautes-Provence, France). Proceedings of the landslide processes conference, Strasbourg, France, 63-68.

21) Mondini, A. C., Chang, K. T. and Yin, H. Y. (2011): Combining multiple change detection indices for mapping landslides triggered by typhoons. Geomorphology, 134(3-4), 440-451.

22) Osanai, N., Shimizu, T., Kuramoto, K., Kojima, S. and Noro, T. (2010): Japanese early-warning for debris flows and slope failures using rainfall indices with Radial Basis Function Network. Landslides, 7(3), 325-338.

23) Razak, K. A., Santangelo, M., Van Westen, C. J., Straatsma, M. W. and de Jong, S. M. (2013): Generating an optimal DTM from airborne laser scanning data for landslide mapping in a tropical forest environment. Geomorphology, 190, 112-125.

24) Soeters, R. and van Westen, C.J. (1996): Slope instability recognition, analysis, and zonation. In: Landslides, investigation and mitigation. ISBN 0-309-06151-2, Transportation Research Board, National Research Council, Special Report 247, 129-177.

25) Stumpf, A. and Kerle, N. (2011): Object-oriented mapping of landslides using Random Forests. Remote Sensing of Environment, 115(10), 2564-2577.

26) Turkington, T., Ettema, J., van Westen, C. J. and Breinl, K. (2014): Empirical atmospheric thresholds for debris flows and flash floods in the Southern French Alps. Natural Hazards and Earth System Sciences, Discussions, 2, 757-798.

27) Vessia, G., Parise, M., Brunetti, M. T., Peruccacci, S., Rossi, M., Vennari, C. and Guzzetti, F. (2014): Automated reconstruction of rainfall events responsible for shallow landslides. Natural Hazards and Earth System Sciences Discussions, 2, 2869-2890.

28) Wei, L. W., Chen, H., Lee, C. F., Huang, W. K., Lin, M. L., Chi, C. C. and Lin, H. H. (2014): The mechanism of rockfall disaster: A case study from Badouzih, Keelung, in northern Taiwan. Engineering Geology, 183(9), 116-126.

29) Wei, L. W., Lee, C. F., Huang, C. M., Huang, W. K., Lin, H. H. and Chi, C. C. (2015): A preliminary study of the rainfall threshold and early warning system for landslide in Taiwan. Engineering Geology for Society and Territory, 2, 1571-1574.

30) Wu, C. H., Chen, S. C. and Chou, H. T. (2011): Geomorphologic characteristics of catastrophic landslides during typhoon Morakot in the Kaoping Watershed, Taiwan. Engineering Geology, 123(1), 13-21.

31) Xie, M., Esaki, T. and Zhou, G. (2004): GIS-based probabilistic mapping of landslide hazard using a three-dimensional deterministic model. Natural Hazards, 33(2), 265-282.

32) Zhou, W., Tang, C., Van Asch, T. W. and Zhou, C. (2014): Rainfall-triggering response patterns of post-seismic debris flows in the Wenchuan earthquake area. Natural Hazards, 70(2), 1417-1435. 